\title{
Chuva de sementes em remanescente de Caatinga, Porto da Folha, Sergipe, Brasil
}

\author{
Francineide Bezerra Gonçalves ${ }^{1}$ Robério Anastácio Ferreira ${ }^{1}$ Dráuzio Correia Gama ${ }^{2 *}$ \\ Bruno Antonio Lemos de Freitas ${ }^{1}$
}

${ }^{1}$ Universidade Federal de Sergipe. Av. Marechal Rondon, s/n - Jardim Rosa Elze, São Cristóvão, CEP: 49100-000, Sergipe, SE, Brasil
2 Universidade Estadual do Sudoeste da Bahia. Estrada do Bem-Querer, km 04, CEP 45083-900, Vitória da Conquista, BA, Brasil.

\begin{abstract}
Artigo Original
*Autor correspondente: drauziogama@hotmail.com

Palavras-chave:

Diásporos

Síndromes de dispersão

Regeneração natural

Conservação

Keywords:

Diaspore

Dispersal syndromes

Natural regeneration

Conservation

Received in

RESUMO: Estudos sobre dispersão e chuva de sementes proporcionam informações valiosas sobre padrões de dispersão, entradas e saídas de diásporos assim como na abundância, distribuição espacial, densidade e riqueza de espécies. Objetivou-se identificar as estratégias de estabelecimento de espécies vegetais quanto às síndromes de dispersão e composição da chuva de sementes em remanescente de Caatinga no município de Porto da Folha-Sergipe. Para a avaliação quali-quantitativa da chuva de sementes foram instalados 25 coletores (confeccionados em madeira), a $50 \mathrm{~cm}$ acima do solo. Contabilizou-se 4.248 sementes, pertencentes a 40 táxons, dos quais foram identificados 28 ao nível de espécie, quatro ao nível de gênero e 12 classificados como indeterminados. As espécies identificadas pertencem a 17 famílias botânicas e são compostas por quatro hábitos vegetacionais: árvores, arbustos, herbáceas e lianas. A síndrome de dispersão predominante na área, considerando-se o número de espécies identificadas, foi a autocoria (32,5\%), seguida da anemocoria $(20 \%)$ e a zoocoria $(17,5 \%)$. Quanto à densidade de deposição de sementes, a síndrome de dispersão predominante foi anemocoria $(34,7 \%)$, sendo superior à autocoria $(31,5 \%)$ e à zoocoria $(4,3 \%)$. A chuva de sementes atua efetivamente na autoregeneração da comunidade vegetal, em virtude da riqueza e abundância de sementes depositadas durante os meses de avaliação.
\end{abstract}

2020/19/07

Accepted on

2021/22/01

Published in

2021/30/06

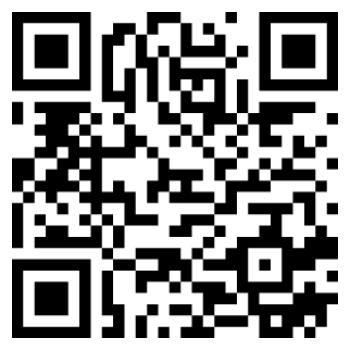

DOI:

Https://doi.org/10.34062/afs .v8i1.10849

\section{(cc) BY}

\section{Seed rain in Caatinga remnants, Porto da Folha, Sergipe, Brazil}

\begin{abstract}
Studies on the dispersion and seed rain provide valuable information on dispersion standards, entrances and exits of seeds, as well as in the abundance, spatial distribution, density and species richness. This study aims to identify the strategies of establishment of plant species for the dispersion syndromes and composition of the rainfall of seeds in the Caatinga remnant in the county of Porto da Folha, Sergipe. For quali-quantitative evaluation of the seed rain, 25 collectors (confectioned in wood) were installed at $50 \mathrm{~cm}$ above of the ground. 4248 seeds belonging to 40 taxons were counted, from which 28 were identified to species level, four to genus and 12 classified as indeterminate. The identified species belong to 17 botanical families and are composed for four vegetation habits: trees, shrubs, herbs and lianas. The syndrome of predominant dispersion in the area, considering the number of identified species, was the ballistic dispersal $(32,5 \%)$, followed of the anemochory $(20 \%)$ and the zoochory $(17,5 \%)$. As for the seeds density, the predominant dispersion syndrome found was anemocory $(34,7 \%)$, exceeding the autocory $(31,5 \%)$ and the zoochory $(4,3 \%)$. The seed rain acts effectively in the selfregeneration of the vegetal community.
\end{abstract}


Introdução

A paisagem florestal é constituída por uma composição florística variada entre diferentes indivíduos de espécies e famílias botânicas, possibilitada pela perpetuação e a interação entre elas através da dispersão de sementes, principalmente (Medeiros et al. 2015). Essa dispersão, como sendo o primeiro estágio da colonização e fator potencial de recrutamento florestal (Castillo e Rios 2008), respondem pelo estoque de sementes disponíveis no solo (Paz et al. 2016).

Diversos são os agentes que contribuem para que as sementes se afastem da planta-mãe, entre eles os agentes dispersores abióticos por mecanismos hidrocórico (dispersão pela água), anemocórico (vento) e barocórico (gravidade) e os bióticos evidenciando padrões zoocóricos como aves, formigas e pequenos mamíferos, por exemplo, os quais variam de acordo com as características das sementes e frutos.

O mecanismo funcional na regeneração natural de uma floresta é, pelo menos em parte, determinado por meio da chuva de sementes (PietroSouza et al. 2014), a qual estabelece parte da população potencial de um ecossistema quando este, constantemente, recebe por propágulos advindos de alguma população externa (alóctones) ou da própria área (autóctone) contribuindo pela diversidade de sementes estocada no solo, do qual também depende a manutenção de uma floresta (Araújo et al. 2004; Santos et al. 2018).

Mesmo havendo constância na riqueza na chuva das sementes ao longo do tempo, a composição gradualmente muda quando a dispersão ocorre por animais, o que produz um aumento adicional de riqueza (Martínez-Garza et al. 2011), além de mudança da composição e dispersão por influências climáticas.

A vegetação da Caatinga, adaptada ao clima semiárido com estações de secas prolongadas e de chuvas concentradas em curto prazo de tempo, é influenciada por essa sazonalidade climática que responde na riqueza e número de sementes (Santos et al. 2010). Desse modo, as sementes produzidas durante todo o ano, com maioria dispersa no final da estação seca, apresentam características morfofisiológicas de acordo com os locais onde são produzidas (Dantas et al. 2014), visto que, a maioria torna-se apta a germinar após o início das primeiras chuvas (Araújo et al. 2014).

Diante do contexto, tendo como princípio básico a chuva de sementes, estudos que caracterizem as estratégias de dispersão e estabelecimento de comunidades vegetais são de fundamental importância para compreensão das interações existentes, dinâmica de evolução e sucessão em remanescentes florestais, visando à manutenção e conservação da biodiversidade "in situ" e "ex situ", disponibilizando assim, informações que podem auxiliar na elaboração de planos de manejo, programas de recuperação de áreas degradadas e uso sustentável pelas comunidades tradicionais dos recursos naturais disponíveis no bioma Caatinga, além de gerar informações sobre recursos disponíveis para frugívoros e granívoros.

Nesse sentido, o trabalho foi realizado com o objetivo de identificar as estratégias de estabelecimento de espécies vegetais quanto às síndromes de dispersão e a composição da chuva de sementes em remanescente de Caatinga no município de Porto da Folha, Sergipe.

\section{Material e Métodos}

Caracterização da área de estudo

A área de estudo localiza-se em um fragmento de Caatinga arbórea em bom estado de conservação com área de 49,84ha (Lat. 673603 e 674786 W; Long. 8889897 e 8890909 S) e sem conexão com outras áreas próximas, no município de Porto da Folha, situado no Alto Sertão Sergipano formado, predominantemente, por solos Neossolos litólicos e Planossolos.

O clima da região é do tipo BSh, caracterizado como quente e seco, segundo a classificação de Köppen, com precipitações irregulares e mal distribuídas (Alvares et al. 2013).

O período seco da região é superior a oito meses com chuvas condicionadas a um período reduzido (março a julho) e maiores índices de precipitação registrados em abril (CEMESE 2012).

Em 2011, registrou-se 564,2 $\mathrm{mm}$ com abril sendo o mês mais chuvoso $(133 \mathrm{~mm})$ e dezembro o mais seco (00 mm) (CEMESE 2012). A temperatura média anual é de $25,6^{\circ} \mathrm{C}$, sendo dezembro o mês mais quente e agosto o mais frio (CEMESE 2012). (Figura 1).

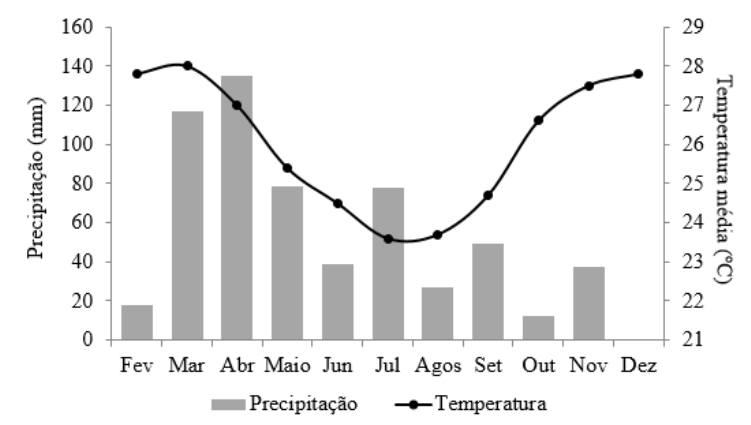

Figura 1. Precipitação e temperatura média em para o município de Porto da Folha-SE.

\section{Avaliação da chuva de sementes}

$\mathrm{Na}$ área de estudo foram distribuídas 25 parcelas de $20 \mathrm{~m}$ x $20 \mathrm{~m}$. O valor da distância entre as parcelas de $141,19 \mathrm{~m}$ foi estabelecido de acordo com o intervalo de amostragem " $k$ ", obtido a partir da raiz quadrada da divisão da área total $\left(\mathrm{A}=498.400 \mathrm{~m}^{2}\right)$ pelo número de unidades amostrais $(n=25$ parcelas $)$. 
Paralelamente, foi realizado estudos de florística, fitossociologia e de fenologia pelo método de amostragem de área fixa.

Ao centro de cada parcela foi instalado um coletor confeccionado em madeira nas dimensões de $1 \mathrm{~m} \mathrm{x} 1 \mathrm{~m}\left(1 \mathrm{~m}^{2}\right)$ e tela de nylon de malha fina $(1 \mathrm{~mm})$ com $10 \mathrm{~cm}$ de profundidade a $50 \mathrm{~cm}$ acima do solo.

\section{Obtenção e interpretação dos dados}

As avaliações foram realizadas mensalmente por um período de 11 meses (fevereiro a dezembro de 2011), coletando todo o material depositado, acondicionando-os em sacos plásticos etiquetados e conduzidos ao Laboratório de Dendrologia e Ecologia Florestal da Universidade Federal de Sergipe, para posterior triagem, identificação e quantificação. Frutos maduros encontrados nos coletores tinham suas sementes retiradas e contabilizadas no estudo, descartando os imaturos.

Os táxons foram identificados com auxílio de literatura especializada, por comparação com sementes recolhidas na área durante as coletas e por duplicatas no herbário da Universidade Federal de Sergipe (ASE), classificadas ao nível de família, gênero e espécie conforme o Sistema Angiosperm Phylogeny Group IV (Chase et. 2016). Os táxons não identificados foram considerados indeterminados.

As síndromes de dispersão dos táxons encontrados na chuva de sementes foram classificadas de acordo com as categorias anemocóricas, zoocóricas e autocóricas. As sementes também foram classificadas conforme o sistema de classificação de formas de vida de Raunkiaer quanto aos hábitos vegetacionais (arbóreo, arbusto, herbário e lianas) com base em Martins e Batalha (2013).

Realizou-se uma classificação morfológica dos frutos observando a deiscência, consistência e tipo de fruto (Barroso et al. 2004) por meio da análise do material coletado durante o estudo. Quando os frutos não foram amostrados nos coletores, procedeu-se à coleta destes em indivíduos da mesma espécie presentes na área. Foram coletados frutos imaturos e maduros para auxiliar na identificação, assim como para depósito na carpoteca do Herbário da Universidade Federal de Sergipe (ASE).

\section{Análise dos dados}

Calculou-se a densidade absoluta (DA) de deposição de sementes mensal e total (ind.ha ${ }^{-1}$ ) e frequência absoluta (FA) como proposto por Mueller-Dumbois e Ellenberg (1974). E para análise da diversidade florística foi utilizado o índice de Shannon-Weaver (H') e o índice de equabilidade de Pielou (J'), conforme Pielou (1975) e Magurran (1988). Utilizou-se, para a obtenção dos parâmetros e índices avaliados, de planilha Excel Microsoft Windows 2007.

\section{Resultados e Discussão}

Durante os meses de coleta foram contabilizadas 4.248 sementes, pertencentes a 17 famílias botânicas em 28 espécies e 12 táxons indeterminados, distribuídos por número de sementes pelo tipo de hábito arbóreo, arbustivo, herbáceo e lianas (Tabela 1).

Dentre as famílias botânicas amostradas destacaram-se Fabaceae, com seis espécies (quatro pertencendo ao hábito vegetacional arbóreo e duas lianas) e Euphorbiaceae, com cinco espécies (quatro arbustivas e uma herbácea). Apenas estas duas famílias apresentaram espécies com diferentes hábitos. As demais apresentaram apenas um hábito, mesmo com mais de uma espécie cada.

Com relação ao número de sementes depositadas por família botânica, Anacardiaceae, representada por duas espécies arbóreas ( $M$. urundeuva e $S$. brasiliensis), com síndrome de dispersão anemocórica, foi a que mais depositou sementes $(n=1.376,32,4 \%)$.

Porém a densidade, a época e o pico de produção e de deposição diferiram entre as espécies: $S$. brasiliensis com maior deposição de sementes durante os meses de maiores índices pluviométricos (março e abril) e M. urundeuva no período seco, com pico de produção em dezembro (Quadro 1).

A família Vitaceae com apenas duas espécies lianas ( $C$. sicyoides e $C$. trigona) e síndrome de dispersão zoocórica, foi a segunda em número de sementes ( $\mathrm{n}=985,23,2 \%)$, tendo $C$. sicyoides com as maiores densidades realizadas em julho e agosto e $C$. trigona, com pico de deposição em agosto, apresentou densidade bastante inferior à obtida por C. sicyoides.

Com maior número de espécies em quatro arbóreas $(P$. pyramidalis e $B$. cheilantha. A. colubrina e $P$. stipulacea) e duas lianas (Aeschynomene sp. e V. peduncularis), a família botânica Fabaceae apresentou baixa deposição de sementes $(n=626,14,73 \%)$. Dentre as arbóreas, $B$. cheilantha contribuiu com maior deposição em todo o período seco em maior número ocorrido em outubro. A maior frequência de deposição (em 10 dos 11 meses de coleta) e maior densidade registrada no período seco, com maior deposição em outubro, ocorreram com A. colubrina. As espécies lianas, $V$. peduncularis e Aeschynomene sp., apresentaram maiores densidades também na estação seca. Deste modo, pode-se inferir que a chuva de sementes encontradas em Fabaceae é dispersa no final do período chuvoso e seco, sendo $B$. cheilantha mais frequente nesse processo. 
Tabela 1. Composição florística, síndrome de dispersão (SD), tipo de fruto (TF) e tipo de deiscência (DS), em avaliação de chuva de sementes em remanescente de Caatinga no município de Porto da Folha-SE, Brasil, 2011.

\begin{tabular}{|c|c|c|c|c|c|}
\hline Família - Espécie & Nome popular & Hábito & SD & TF & DS \\
\hline \multicolumn{6}{|l|}{ ACANTHACEAE } \\
\hline Ruellia bahiensis (Nees) Morong & - & Erv & Aut & Clo & $\mathrm{D}$ \\
\hline \multicolumn{6}{|l|}{ ANACARDIACEAE } \\
\hline Myracrodruon urundeuva Allemão & aroeira-do-sertão & Arv & Ane & Dgl & I \\
\hline Schinopsis brasiliensis Engl & braúna & Arv & Ane & Sam & I \\
\hline \multicolumn{6}{|l|}{ ASTERACEAE } \\
\hline $\begin{array}{l}\text { Delilia biflora }(\text { L.) Kuntze } \\
\text { BIGNONIACEAE }\end{array}$ & - & Ver & Ane & Aqu & I \\
\hline $\begin{array}{l}\text { Tabebuia aurea (Silva Manso) Benth. \& Hook. f. ex S. Moore } \\
\text { BURSERACEAE }\end{array}$ & craibeira & Arv & Ane & Csp & $\mathrm{D}$ \\
\hline $\begin{array}{l}\text { Commiphora leptophloeos (Mart.) J.B. Gillett } \\
\text { CELASTRACEAE }\end{array}$ & imburana-de-cambão & Arv & Zoo & Dru & I \\
\hline $\begin{array}{l}\text { Maytenus rigida } \text { Moric } \\
\text { DIOSCOREACEAE }\end{array}$ & \multicolumn{5}{|c|}{ DIOSCOREACEAE } \\
\hline $\begin{array}{l}\text { Dioscorea laxiflora Mart. ex Griseb. } \\
\text { EUPHORBIACEAE }\end{array}$ & caratinga-do-mato & Lia & Ane & $\mathrm{Ctr}$ & $\mathrm{D}$ \\
\hline Cnidoscolus urens (L.) Arthur & cansanção & Erv & Aut & Esq & $\mathrm{D}$ \\
\hline Manihot dichotoma Ule & maniçoba & Arb & Aut & $\mathrm{Coc}$ & $\mathrm{D}$ \\
\hline Croton sonderianus Müll. Arg. & marmeleiro & Arb & Aut & Ctr & $\mathrm{D}$ \\
\hline Croton adenocalix Baill & marmeleiro-branco & Arb & Aut & $\mathrm{Ctr}$ & $\mathrm{D}$ \\
\hline Jatropha molissima (Pohl) Baill & pinhão & Arb & Aut & $\mathrm{Coc}$ & $\mathrm{D}$ \\
\hline \multicolumn{6}{|l|}{ FABACEAE } \\
\hline \multicolumn{6}{|l|}{ Caesalpinioideae } \\
\hline Poincianella pyramidalis (Tul.) L.P. Queiroz & catingueira & Arv & Aut & Leg & D \\
\hline $\begin{array}{l}\text { Bauhinia cheilantha (Bong.) Steud. } \\
\text { Faboideae }\end{array}$ & mororó & Arv & Aut & Leg & $\mathrm{D}$ \\
\hline Aeschynomene sp. & - & Lia & Aut & Lom & $\mathrm{D}$ \\
\hline $\begin{array}{l}\text { Vigna peduncularis (Kunth.) Fawc. \& Rendle } \\
\text { Mimosoideae }\end{array}$ & - & Lia & Aut & Leg & $\mathrm{D}$ \\
\hline Anadenanthera colubrina (Vell.) Brenan & angico-de-caroço & Arv & Aut & Fol & $\mathrm{D}$ \\
\hline $\begin{array}{l}\text { Piptadenia stipulacea (Benth.) Ducke } \\
\text { MALPIGHIACEAE }\end{array}$ & arranhento & Arv & Aut & $\operatorname{Lg}$ & $\mathrm{D}$ \\
\hline $\begin{array}{l}\text { Heteropterys sp. } \\
\text { MALVACEAE }\end{array}$ & - & Lia & Ane & Sam & I \\
\hline $\begin{array}{l}\text { Helicteres sp. } \\
\text { MELIACEAE }\end{array}$ & umbigo-de-bode & Arb & Aut & Esq & $\mathrm{D}$ \\
\hline $\begin{array}{l}\text { Cedrela odorata } \mathrm{L} . \\
\text { RHAMNACEAE }\end{array}$ & cedro & Arv & Ane & Csf & $\mathrm{D}$ \\
\hline $\begin{array}{l}\text { Ziziphus joazeiro Mart. } \\
\text { RUBIACEAE }\end{array}$ & juazeiro & Árv & Zoo & Dru & I \\
\hline $\begin{array}{l}\text { Guettarda sericea Müll. Arg. } \\
\text { SAPINDACEAE }\end{array}$ & veludo & Arb & Zoo & Dru & I \\
\hline $\begin{array}{l}\text { Serjania } \text { sp. } \\
\text { SAPOTACEAE }\end{array}$ & cipó-amarra-cachorro & Lia & Ane & Sam & I \\
\hline $\begin{array}{l}\text { Sideroxylon obtusifolium (Humb. Ex Roem. \& Schult.) T.D. } \\
\text { Penn. } \\
\text { VITACEAE }\end{array}$ & quixabeira & Arv & Zoo & $\mathrm{Bac}$ & I \\
\hline Cissus sicyoides $\mathrm{L}$. & cipó-pucá & Lia & Zoo & Dru & I \\
\hline $\begin{array}{l}\text { Cissus trigona Willd. ex Roem. \& Schult. } \\
\text { INDETERMINADA }\end{array}$ & vermelho & Lia & Zoo & Dru & I \\
\hline $1,2,3,4,5,6,7,8,9,10,11,12$ & - & - & - & - & - \\
\hline
\end{tabular}

Onde: deiscente (D), indeiscente (I), erva (Erv), árvore (Arv), liana (Lia), arbusto (Arb), autocórica (Aut), anemocórica (Ane), zoocórica (Zoo), cápsula loculicida (Clo), cápsula septicida (Csp), cápsula septígrafa (Csf), cápsula trialada $(\mathrm{Ctr})$, cápsula tricoca $(\mathrm{Ctr})$, drupa $(\mathrm{Dru})$, drupa globosa $(\mathrm{Dgl})$, sâmara $(\mathrm{Sam})$, aquênio (Aqu), esquizocarpo (Esq), coca (Coc), legume (Leg), lomento (Lom), folículo (Fol) e bacóide (Bac).

Euphorbiaceae contribuiu com um número de $579(13,6 \%)$ sementes entre as cinco espécies autocóricas sendo quatro arbustivas (C. sonderianus, C. adenocalix, J. molissima e M. dichotoma) e uma herbácea (C. urens), responderam a 13,6\% do total de sementes quantificadas no estudo.

C. sonderianus, seguida de C. adenocali foram as espécies que mais contribuíram no processo de dispersão com picos de deposição em abril e 
maio, sendo estes os meses de maior precipitação. Já a única herbácea desta família exibiu pico de produção em março.

A dispersão das sementes ocorridas em períodos diferentes, tanto entre famílias botânicas quanto dentre as suas espécies e pelas variadas formas de vida, está relacionada, possivelmente, ao aspecto fenológico da formação das sementes de cada espécie própria de cada época.

Por outro lado, a maior produção/deposição de sementes, pode ser entendida, provavelmente, como um atributo ecológico potencialmente favorável das espécies para a formação de banco de sementes no solo como estratégia de contínua colonização do ecossistema, como uma característica de espécies pioneiras, a exemplo de $M$. urundeuva e $S$. brasiliensis observadas.

O hábito com maior número de táxons foi o arbóreo, composto por 12 espécies (A. colubrina, $B$. cheilantha, C. odorata, C. leptophloeos, M. rigida, M. urundeuva, $P$. stipulacea, $P$. pyramidalis, $S$. brasiliensis, S. obtusifolium, T. aurea e Z. joazeiro) que perfizeram $53,3 \%$ do total de sementes quantificadas (Figura 2).

As lianas compõem o segundo hábito com maior número de táxons (sete) sendo quatro identificados ao nível de espécie ( $C$. sicyoides, $C$. trigona, D. laxiflora e $V$. peduncularis) e três ao de gênero (Aeschynomene sp., Heteropterys sp. e Serjania sp.) representando $24,9 \%$ das sementes depositadas. Já o hábito arbustivo com cinco espécies ( $C$. sonderianus, $C$. adenocalix, $J$. molissima, $M$. dichotoma e $G$. sericea) e um táxon identificado até o gênero (Helicteres sp.) representaram $13,3 \%$ das sementes. Com três espécies (C. urens, D. biflora e R. bahiensis), o herbáceo respondeu com 4,2\% das sementes. E 12 táxons indeterminados $(4,3 \%)$ das sementes depositadas.

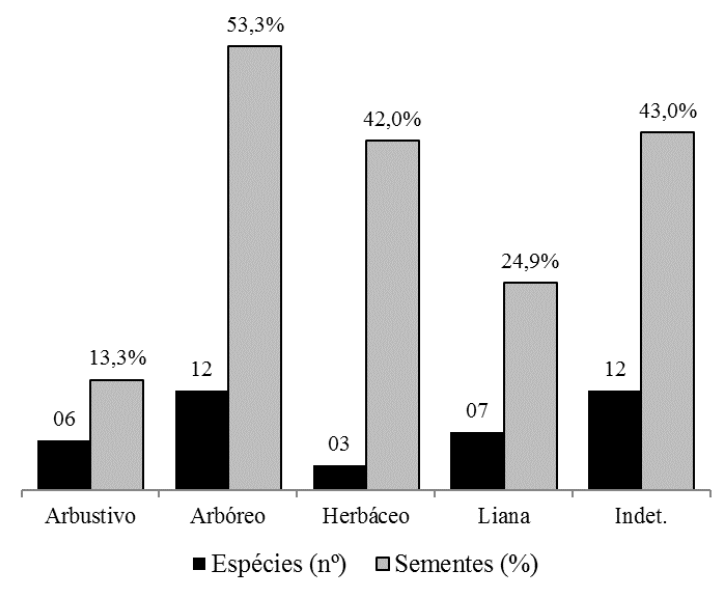

Figura 2. Número e porcentagem de sementes em cada hábito vegetacional (arbustivo, arbóreo, herbáceo e liana) e indeterminadas (indet.) em avaliação da chuva de sementes em fragmento de
Caatinga no município de Porto da Folha-SE, Brasil, 2011.

A deposição de sementes correspondeu a três síndromes de dispersão: autocórica (balística), anemocórica e zoocórica. A síndrome predominante na área, considerando o número de espécies identificadas, foi a autocoria $(32,5 \%)$, seguida da anemocoria $(20,0 \%)$ e zoocoria $(17,5 \%)$ (Figura 3A). Em termos de densidade, predominou a anemocórica $(34,7 \%)$ seguida da autocórica $(31,5 \%)$. A síndrome zoocórica respondeu com apenas 4,3\% das sementes depositadas (Figura 3B).

$\mathrm{O}$ pico, em número de espécies autocóricas dispersando, ocorreu em agosto $(n=10)$ e setembro $(n=8)$ coincidindo com o final do período chuvoso e início da estação seca, sendo estas as espécies $A$. colubrina, B. cheilantha, $C$. urens, $C$. adenocalix, $C$. sonderianus, J. molissima, $M$. dichotoma, $P$. stipulacea, $R$. bahiensis e $V$. peduncularis.
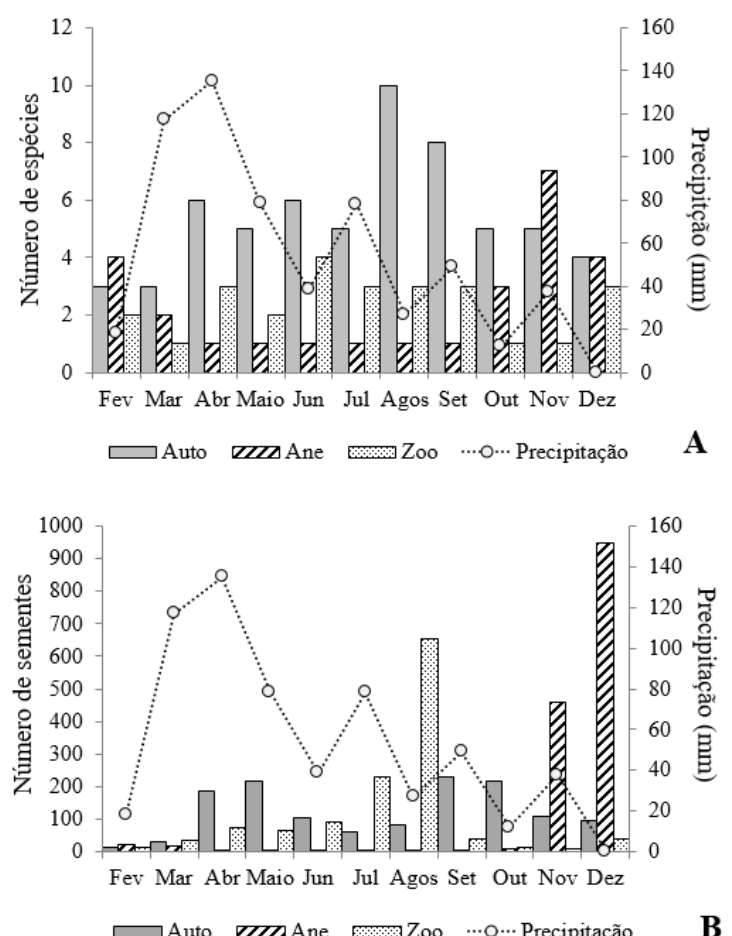

Figura 3. Número de espécies (A) e de sementes (B) depositadas nos coletores conforme a síndrome de dispersão (Auto: autocórica; Ane: anemocórica; Zoo: zoocórica) em avaliação da chuva de sementes em fragmento de Caatinga no município de Porto da Folha-SE, Brasil, 2011.

As maiores deposições de sementes autocóricas ocorreram no período seco, sendo $B$. cheilantha responsável pela maior densidade com pico nos meses de setembro $(61,5 \%)$ e outubro $(60,3 \%)$. No período chuvoso, foram observados valores próximos aos obtidos no pico de deposição das sementes do período seco, destacando-se $C$. sonderianus com 45,0\% em abril e 41,6\% em maio. 
Resultado semelhante foi obtido por Lima et al. (2008) que identificaram a autocoria predominante em número de espécies durante o período chuvoso e número de deposição de sementes semelhantes nos períodos seco e chuvoso. Para Foster (1992), a época de dispersão das espécies é controlada pelo período que apresenta as condições mais favoráveis para a germinação de suas sementes, demonstrando maior dispersão no período chuvoso.

$\mathrm{Na}$ Caatinga dos municípios de Canindé de São Francisco-SE e Poço Redondo-SE, Silva et al. (2013a) observaram superioridade de frutos secos $(68,7 \%)$ dispersados, predominando a síndrome abiótica $(61,2 \%)$, principalmente a autocoria (43\%), prevalecendo nos estrato herbáceo $(52 \%)$ e arbustivo-arbóreo (46\%) com pequena diferença percentual em relação à zoocoria $(38,8 \%)$. Já Silva et al. (2012) em um trecho de mata ciliar no município de Sirinhaém-PE, observaram predomínio da zoocoria $(72,8 \%)$, seguida pela autocoria $(13,6 \%)$ e anemocoria $(4,8 \%)$.

Griz e Machado (2001) para duas espécies de Croton sp, das quais uma é o C. sonderianus, relatam que a síndrome de dispersão autocórica (balística) realizada por estas espécies possui bastante relação com a ocorrência da chuva. Para Van Der Pjil (1982), os pingos de chuva geralmente atuam como gatilho, promovendo a deiscência dos frutos e a posterior disseminação das sementes autocóricas no período chuvoso, destacando o gênero Croton $\mathrm{sp}$.

A ocorrência de espécies anemocóricas e os índices de produção e deposição de suas sementes se deram em maior proporção no período seco (final do período seco de 2010 e novembro e dezembro de 2011). Entretanto, novembro se destacou por concentrar o maior número de espécies (sete) respondendo com deposição de sementes anemocóricas. Em dezembro foram identificadas apenas quatro espécies com maior número de sementes anemocóricas depositadas $(n=949)$ representando $22,3 \%$ do total de sementes.

Das sementes anemocóricas depositadas, $M$. urundeuva contribuiu consideravelmente com $88,7 \%$ em novembro e 98,8\% em dezembro. Provavelmente, esse alto percentual seja decorrente do fato dela ser uma espécie pioneira e com frutos de tamanho bastante reduzido, de $2,8 \mathrm{~mm}$ a $3,9 \mathrm{~mm}$ de comprimento, conforme Feliciano et al. (2008).

Nos hábitos arbóreos e lianas, predominantes na área, destacaram-se pela anemocoria. Van Der Pjil (1982) e Howe e Smallwood (1982) explicam que essa síndrome é uma característica de espécies de estádios iniciais da sucessão de árvores e lianas. Geralmente as espécies anemocóricas se dispersam na estação seca antes do início das chuvas e com maior ação da força dos ventos (Howe e Smallwood bahiensis e B. cheilantha em densidade e deposição contínua. Seguida de $M$. urundeuva, D. biflora e as Indeterminadas 6 e 7.
1982, Griz e Machado 2001), favorecendo a dispersão em intervalos mais eficientes que os animais (Du et al. 2012).

Em épocas chuvosas se observou menor ocorrência ou ausência de alguns diásporos anemocóricos, explicado, possivelmente, pela presença da estrutura morfológica adaptada ao vôo (presença de alas) que, quando molhados pela chuva, aumentam a razão peso/área, impedindo-as de alcançarem maiores distâncias na dispersão (Van Der Pijl 1982).

Observando os meses chuvosos em sequência de precipitação decrescente, a densidade de espécies dispersas por zoocoria, manteve-se praticamente constante, até setembro. Sendo que no mês de junho observou-se um número de quatro espécies e de julho a setembro em três espécies (Figura 3A).

Com relação a deposição de sementes, nesse mesmo período de chuvas, ocorreu aumento com picos de deposição de sementes verificados em julho $(\mathrm{n}=228)$ e, principalmente, agosto $(\mathrm{n}=655)$ (Figura 3B). Nestes dois meses as sementes zoocóricas predominaram com $77,3 \%$ e $87,6 \%$, respectivamente.

Em termos de densidade, $C$. sicyoides foi a que mais contribuiu em deposição zoocórica nos meses de julho (75,3\%) e agosto (84,2\%). Geralmente, conforme Griz e Machado (2001), as espécies zoocóricas apresentam amadurecimento de seus frutos e dispersão de seus diásporos no início ou no meio da estação chuvosa.

Com relação às espécies que ainda não foram identificadas, classificadas como indeterminadas, verificou-se um maior número de táxons nos meses da estação seca (outubro a dezembro) com maior número em novembro $(\mathrm{n}=7)$. Quanto à deposição de sementes, outubro foi o mês com maior densidade, das quais $93,1 \%$ pertencem ao táxon classificado como Indeterminada 6.

Com maior número de espécies, o hábito arbóreo apresentou diferentes estratégias de síndrome de dispersão, o que pode ser explicado. Situação também semelhante entre as lianas, embora com menor número de espécies para a zoocoria e autocoria em comparação a árborea.

A anemocoria foi a segunda maior síndrome de dispersão ocorrendo em três dos quatro hábitos (liana, árvore e herbáceo), com maior número de espécies entre as lianas. A zoocoria também esteve presente em três hábitos (liana, árvore e arbustivo), porém não foi predominante em nenhum deles.

A densidade de sementes durante o período de avalição foi de 67.968 ind.ha $^{-1}$ sendo que, dos 38 táxons amostrados, 22 depositaram sementes no período seco equivalendo a 22.164 ind.ha ${ }^{-1}$ para este período destacando-se $C$. sicyoides, A. colubrina, $R$.

A densidade total de sementes no período chuvoso foi de 3.408 ind.ha $^{-1}$, destacando-se $C$. adenocalix, $C$. sonderianus e $M$. dichotoma com maior contribuição, mas sem deposição continua. As 
espécies $C$. urens, $M$. urundeuva, $Z$. joazeiro e $S$. brasiliensis, mesmo com baixa densidade, apresentaram maior continuidade por todo período chuvoso (Quadro 1).

Os picos de deposição de sementes no período seco ocorreram nos meses de dezembro, agosto e novembro, em ordem de grandeza, sendo agosto representado fortemente pelas espécies de deposição contínua. Já no período chuvoso, apenas março e abril apresentaram as maiores concentrações de deposição.

Em agosto foram depositadas 740 sementes, coincidindo com o final do período chuvoso e início do seco e com maior incidência de espécies com síndrome autocórica, seguida da zoocórica. No entanto, quando se analisou número de sementes, predominou a zoocoria (com destaque para a $C$. sicyoides), representando $88,5 \%$ da densidade total para este mês, seguida da autocoria $(11,2 \%)$. Espécies zoocóricas geralmente dispersam seus diásporos durante ou no final da estação chuvosa e a autocórica em grande parte no final dessa estação (Lima et al. 2007).

Em novembro foi possível verificar a terceira maior densidade de deposição e maior pico ocorrendo em dezembro (auge do período seco), com densidade de 17.488 ind.ha-1. Nestes dois meses foi verificada a predominância de espécies anemocóricas destacando-se $M$. urundeuva com $31,7 \%$ do total de sementes depositadas. Segundo Lima et al. (2008) sementes pequenas, por apresentarem desvantagens em seu estabelecimento, são produzidas em maior quantidade.

O menor valor de deposição em fevereiro de 2011 (relativo ao final do período seco do ano de 2010), seguido pelo mês de março coincide respectivamente com o final do período seco e início do período chuvoso. A maior deposição de sementes ocorreu de agosto a dezembro de 2011, período seco da região, com $72,4 \%$ das sementes depositadas (49.200 ind.ha-1). No período chuvoso (março a julho) verificou-se $27,6 \%$ (18.768 ind.ha-1) das sementes depositadas.

A acentuada deposição de sementes no final do período chuvoso é influenciada pela deposição zoocórica e autocórica. E no período seco, principalmente, pela síndrome anemocórica. Para Morellato et al. (2000) quanto mais sazonal é o clima, menos diversos são os padrões fenológicos em florestas tropicais. E que a diminuição no número de frutos secos ocorre à medida que diminui a sazonalidade, sendo inverso com os frutos carnosos (Silva e Rodal 2009).

Os resultados obtidos corroboram os poucos estudos realizados sobre chuva de sementes em área de Caatinga. Em Pernambuco, Lima et al. (2008) verificaram um maior intervalo de deposição no período seco, apresentando cerca de $65,8 \%$ de sementes depositadas. E Souza (2010) constatou que a densidade da chuva de sementes diferiu significativamente entre estações climáticas, obtendo valores de deposição duas vezes maior na estação seca que na estação chuvosa.

Já em uma mata ciliar no semiárido paraibano, Barbosa (2008) verificou um pico de deposição no início do período seco, especificamente nos meses de agosto e setembro, onde foram depositadas 55,4\% do total de diásporos amostrados. Sobre a variação do número de sementes encontrada por Barbosa (2008), isso pode estar associada, segundo a própria autora, a vários fatores, como a frequência de produção, estratificação da vegetação, dispersores envolvidos e a direção do vento, entre outros.

Em uma área de Caatinga arbustiva-arbórea na estação experimental da Empresa Pernambucana de Pesquisa Agropecuária (IPA), no município de Caruaru-PE com pluviosidade média anual de 662 mm, Silva e Rodal (2009) descreveram 33 espécies (66,6\% com frutos secos) tendo a autocoria com maior ocorrência $(54,5 \%$ das espécies $)$, predominando frutos secos destacando Acacia glomerosa Benh., Croton blanchetianus Baill. e Caesalpinia pyramidalis Tul.; seguida da zoocoria $(33,4 \%)$ apresentando em sua totalidade frutos carnosos, a exemplo de Allophylus quercifolius e Cordia globosa (Jacq) e anemocoria $(12,1 \%)$ com frutos secos, destacando-se a $C$. odorata e $M$. urundeuva.

Também em remanescente de Caatinga arbustiva-arbórea em Reserva Particular do Patrimônio Natural Maurício Dantas (RPPN), no município de Floresta-PE com pluviosidade média anual de $503 \mathrm{~mm}$, Silva e Rodal (2009) encontraram três tipos de síndromes de dispersão: a autocoria com $54 \%$ das espécies, seguida da zoocoria (29\%) e anemocoria (17\%), sendo $70,8 \%$ das espécies descritas tiveram frutos secos.

Já em uma Floresta Estacional Decidual, com precipitação média anual de $1.299 \mathrm{~mm}$, localizada na Estação Ecológica do Tapacurá no município de São Lourenço da Mata-PE, formada por Floresta Estacional Decidual com precipitação média anual de $1.299 \mathrm{~mm}$, Silva e Rodal (2009) observaram 62 espécies com a zoocoria (apresentando frutos carnosos) sendo a síndrome de dispersão mais representativa $(51,6 \%)$, a exemplo de Casearia sylvestris Sw. e Pouteria glomerata (Miq.) Radlk. Seguido da autocoria (incluindo a barocoria) em $38,7 \%$ com maioria de frutos secos, a exemplo de Caesalpinia echinata Lam. e Christiana africana DC. E anemocoria (9,7\%) também com frutos secos como Alseis pickelii Pilg. \& Schmale e Luehea paniculata Mart. 
Golçalves et al.

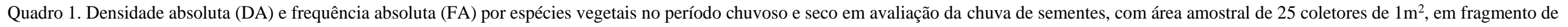
Caatinga no município de Porto da Folha-SE, Brasil, 2011.

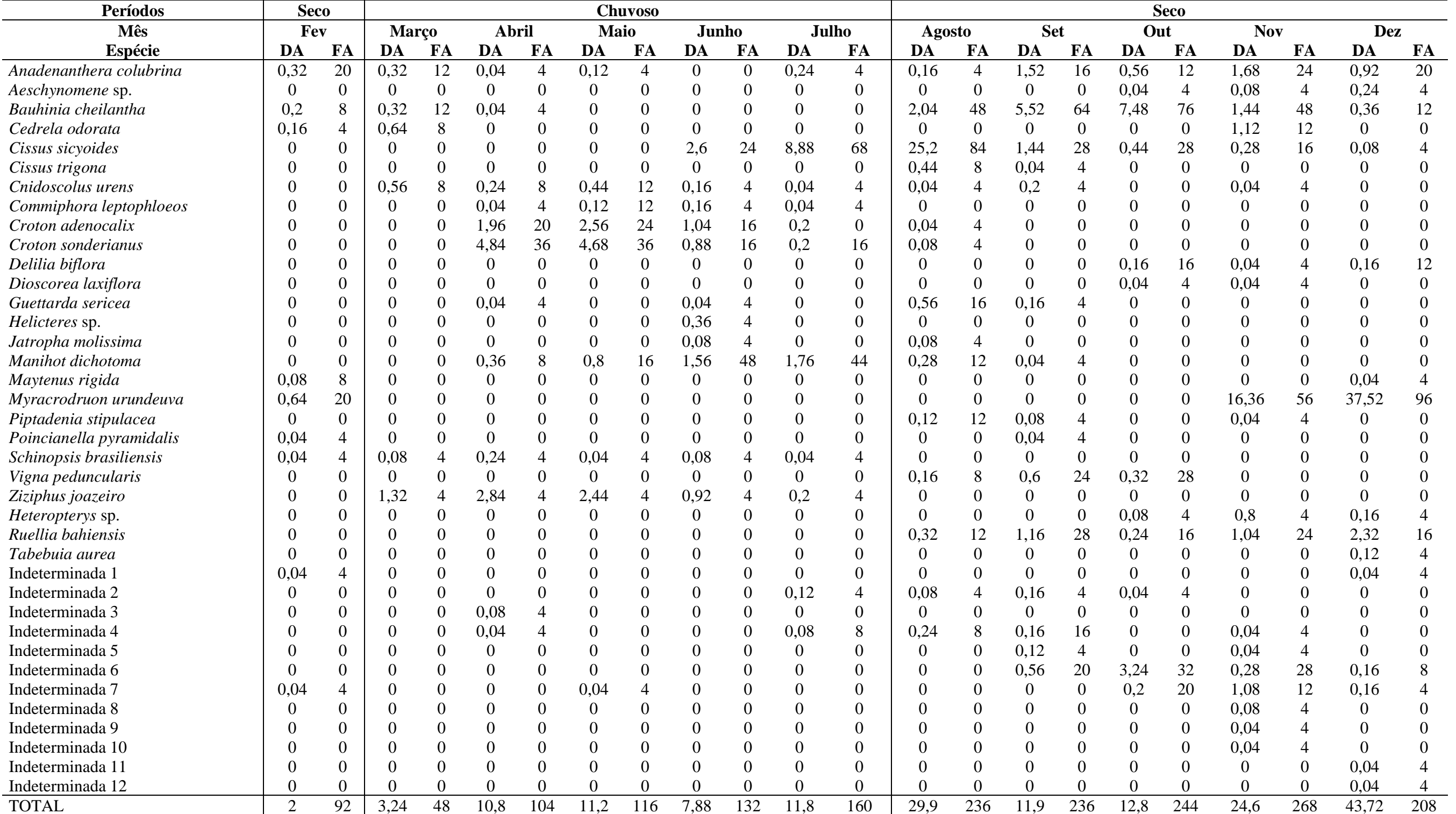


A densidade total de deposição de sementes nos coletores e o número de espécies encontram-se acima do valor observado em estudo semelhante na Reserva Particular do Patrimônio Natural (RPPN), no município de Maurício Dantas-PE, no qual Lima et al. (2008) contabilizaram 756 sementes em $10 \mathrm{~m}^{2}$, distribuídas em 26 táxons (14 identificadas a nível de espécie e 12 indeterminados) pertencentes a 14 famílias.

Barbosa (2008) na caracterização da chuva de sementes em uma área ribeirinha na bacia hidrográfica do Rio Taperoá, semiárido paraibano, coletou em $9 \mathrm{~m}^{2}$ de área amostral, durante um ano, 6.975 sementes pertencentes a 80 táxons, dos quais 32 foram identificados até família e apenas 16 até o nível de espécie, pertencendo a 14 gêneros.

O número de táxons encontrado pela autora é bastante superior ao verificado por Lima et al. (2008). Possivelmente, este maior número de táxons encontrados seja uma resposta à altura dos coletores, neste caso, estando a $15 \mathrm{~cm}$ do solo, facilitando assim a deposição de um maior número de espécies de ervas (ou herbáceas) e/ou Poaceaes que ocupam a fração do piso florestal. No presente estudo e em Lima et al. (2008) foi utilizado coletores a $50 \mathrm{~cm}$ acima do solo.

Souza (2010), em área abandonada após cultivo próxima a um fragmento preservado de Caatinga em Pernambuco, contabilizou 12.445 sementes em $5,58 \mathrm{~m}^{2}$, sendo $66,5 \%$ na estação seca. O número de táxons encontrado para estas sementes foi 56 , dos quais 33 foram identificados em nível de espécie, quatro até família, três até gênero e 16 como indeterminados. O valor encontrado pelo autor é superior aos já citados para área de Caatinga. Dois fatores podem estar relacionados a essa maior deposição de sementes encontrada por Souza (2010): número de coletores utilizados (105 vasos cilíndricos de polietileno), aumentando a possibilidade de coleta de diásporos de diferentes espécies e a fixação dos mesmos, diretamente no solo, podendo ser depositadas sementes de espécies com altura superior a $30 \mathrm{~cm}$ (altura do coletor).

Os valores encontrados no presente estudo ficaram abaixo do verificado por Barbosa (2008) e Souza (2010) para densidade de deposição de sementes em área de Caatinga. Este fato, possivelmente esteja relacionado às variações dos fatores abióticos sobre o meio, existindo diferenças entre precipitação, velocidade do vento, temperatura e umidade relativa do ar, além da composição faunística de cada área que atua na dispersão de frutos e sementes.

As variações encontradas entre os trabalhos de caracterização de chuva de sementes, além de refletir as diferentes formações vegetacionais e estádios sucessionais das florestas analisadas, podem estar relacionadas ao tempo de avaliação (Campos et al. 2009) ou questões metodológicas. Analisando-se a deposição de sementes por hábito, verificou-se que o arbóreo apresentou dispersão contínua de seus diásporos durante o período de avaliação, apresentando maiores densidades de deposição no período seco e pico de deposição no mês de dezembro, com densidade para este mês de 16.120 ind.ha ${ }^{-1}(\mathrm{n}=1.008)$ (Quadro 2).

Quadro 2. Quantificação de sementes por hábito vegetacional (arbóreo, arbustivo, liana e herbáceo) em avaliação da chuva de sementes em fragmento de Caatinga no município de Porto da Folha-SE.

\begin{tabular}{|c|c|c|c|c|c|c|c|c|c|c|c|c|c|}
\hline \multicolumn{14}{|c|}{ Número de sementes durante período de avaliação em 2011} \\
\hline \multirow[b]{2}{*}{ Hábito } & \multicolumn{6}{|c|}{ Período chuvoso } & \multicolumn{5}{|c|}{ Período seco } & \multicolumn{2}{|c|}{ Totais } \\
\hline & $\begin{array}{c}\mathbf{F e} \\
\mathbf{v}\end{array}$ & $\begin{array}{c}\text { Ma } \\
\text { r }\end{array}$ & $\begin{array}{c}\text { Abri } \\
1\end{array}$ & $\begin{array}{c}\text { Mai } \\
\text { o }\end{array}$ & $\begin{array}{c}\mathbf{J u} \\
\mathbf{n}\end{array}$ & Jul & $\begin{array}{c}\mathrm{Ag} \\
\mathbf{0}\end{array}$ & Set & $\begin{array}{c}\mathrm{Ou} \\
\mathbf{t}\end{array}$ & $\begin{array}{c}\text { No } \\
\mathbf{v}\end{array}$ & Dez & $\left(n^{\circ}\right)$ & $(\%)$ \\
\hline Arbóreo & 46 & 67 & 80 & 68 & 29 & 18 & 58 & $\begin{array}{c}17 \\
9\end{array}$ & 201 & 516 & $\begin{array}{c}100 \\
8\end{array}$ & 2270 & $55,8 \%$ \\
\hline Arbustivo & 0 & 0 & 180 & 201 & 99 & 49 & 26 & 5 & 0 & 0 & 0 & 560 & $13,8 \%$ \\
\hline Liana & 2 & 0 & 0 & 0 & 65 & $\begin{array}{c}22 \\
2\end{array}$ & 647 & 55 & 23 & 31 & 12 & 1057 & $26,0 \%$ \\
\hline Herbáceo & 0 & 14 & 6 & 11 & 4 & 1 & 9 & 34 & 10 & 28 & 62 & 179 & $4,4 \%$ \\
\hline
\end{tabular}

As lianas depositaram suas sementes no final do período chuvoso e durante todo o período seco, com pico em agosto. Os arbustos apresentaram deposição no período chuvoso com pico de deposição em maio, representado por $C$. sonderianus com maior produção de sementes.

No final do período chuvoso e início do seco, nos meses de agosto e setembro, verificou-se a deposição de diásporos de espécies arbustivas, das quais a $G$. sericea, espécie zoocórica, contribuiu com $53,8 \%$ e $80,0 \%$, respectivamente, na densidade de deposição dos arbustos nestes dois meses.
Estudos fenológicos apontam a maior incidência de espécies arbustivas frutificando no final da estação chuvosa e início da estação seca, porém no estudo atual observou-se maior deposição no meio do período chuvoso diminuindo gradativamente com a chegada do período seco. As herbáceas depositaram seus diásporos nos dois períodos, porém os maiores picos ocorreram no período seco, destacando-se $R$. bahiensis pela maior influência na deposição em agosto $(98,8 \%)$ e dezembro $(93,5 \%)$ do número total de sementes para este hábito. 
Espécies herbáceas geralmente germinam e crescem na estação chuvosa, dispersando sementes e morrendo na estação seca (Araújo et al. 2007, Lima et al. 2007). Contudo, contribuem em densidade e riqueza pela dispersão e estoque de sementes com grande importância ecológica à conservação do solo, proteção da ação direta dos processos erosivos e formação de microclima favorável para outras espécies (Silva et al. 2013b, Ribeiro et al. 2017).
O resultado obtido reflete maior número de espécies depositando sementes em quantidades semelhantes entre os meses avaliados, com exceção de fevereiro apresentando a menor deposição $(n=50)$. Entretanto, fevereiro foi o mês com a maior diversidade: 1,97 (H') e o segundo maior equabilidade: $0,82\left(\mathrm{~J}^{\prime}\right)$, correspondendo ao final do período seco de 2010 (Tabela 2).

Tabela 2. Número de sementes (N), número de espécies (S), índices de diversidade de Shannon-Weaver (H') e equabilidade de Pielou (J') em avaliação da chuva de sementes em fragmento de Caatinga no município de Porto da Folha-SE, Brasil, 2011.

\begin{tabular}{lrrrr}
\hline \multicolumn{1}{c}{ Mês } & $\mathbf{N}$ & $\mathbf{S}$ & $\mathbf{H}^{\prime}$ & $\mathbf{J}^{\prime}$ \\
\hline Fevereiro & 50 & 11 & 1,97 & 0,82 \\
Março & 81 & 6 & 1,54 & 0,86 \\
Abril & 269 & 12 & 1,44 & 0,58 \\
Maio & 281 & 9 & 1,49 & 0,68 \\
Junho & 197 & 11 & 1,87 & 0,78 \\
Julho & 295 & 11 & 0,92 & 0,38 \\
Agosto & 748 & 16 & 0,75 & 0,27 \\
Setembro & 298 & 16 & 1,82 & 0,66 \\
Outubro & 321 & 12 & 0,52 \\
Novembro & 615 & 20 & 1,38 & 0,46 \\
Dezembro & 1093 & 16 & 0,68 & 0,25 \\
\hline Geral & $\mathbf{4 2 4 8}$ & $\mathbf{2 , 2 4}$ & $\mathbf{0 , 6 1}$ \\
\hline
\end{tabular}

Em dezembro, inversamente observou-se maior número de espécies com deposição de sementes de proporcionalidade variada, ocasionando valores de 0,68 (H') e de 0,25 (J'), com 1.093 sementes depositadas, das quais 938 foram de $M$. urundeuva enquanto outras quatro espécies com apenas uma semente cada contribuiram, efetivamente, ao menor valor de equabilidade (J').

Esse período denota, portanto, menor diversidade de espécies disponíveis para a dispersão de sementes, predominando poucas espécies depositando sementes em abundância.

A diversidade calculada para todas as espécies foi de 2,24 (H') e equabilidade de 0,61 (J'), resultando em uma acentuada diversidade quanto à composição florística e forte heterogeneidade quanto à densidade de deposição de sementes (ou indivíduos) entre estas espécies.

Valores próximos foram obtidos por Barbosa (2008) em mata ciliar no semiárido paraibano, com índice de diversidade para a chuva de sementes de 2,638 (H') e equabilidade de 0,602 (J'), com elevada variação na densidade de deposição entre as espécies, com destaque às herbáceas.

\section{Conclusões}

A chuva de sementes no fragmento de Caatinga avaliado foi composta por 38 táxons, os quais apresentaram maior produção e deposição de diásporos no período seco, com $72,4 \%$ do total das sementes depositadas e densidade 49.200 ind.ha ${ }^{-1}$ neste período.
A síndrome de dispersão predominante na área, considerando-se o número de espécies, foi a autocoria, prevalecendo nos hábitos arbustivo e herbáceo.

Com relação à densidade de sementes por síndrome de dispersão e hábito vegetacional, foi possível observar uma maior densidade de deposição de sementes do hábito arbóreo apresentando síndrome de dispersão anemocórica, seguida da deposição de sementes de lianas zoocóricas.

Provavelmente, a chuva de sementes atua efetivamente na autoregeneração da comunidade vegetal, em virtude da riqueza e abundância de sementes depositadas durante os meses de avaliação.

\section{Referências}

Alvares CA, Stape, JL, Sentelhas, PC, Gonçalves, JLDM, Sparovek, G (2013). Köppen's climate classification map for Brazil. Meteorologische Zeitschrift, 22(6): 711-728. DOI: https://doi.org/10.1127/0941-2948/2013/0507.

Araújo EL, Castro CC, Albuquerque UP (2007) Dynamics of Brazilian Caatinga: A review concerning the plants, environment and people. Functional Ecology and Communities. 1:15-28.

Araújo FS, Oliveira RF, Lima-Verde LW (2008) Composição, espectro biológico e síndromes de dispersão da vegetação de um inselbergue no domínio da caatinga, Ceará. Rodriguésia, 59(4): 
659-671. DOI: https://doi.org/10.1590/21757860200859403 .

Araújo V, Santos D, Santos J, Nascimento D, Silva K, Araújo E (2014) Influência do status da floresta e da variação sazonal sobre o banco de sementes no semiárido brasileiro. Gaia Scientia, 8(1): 136-149.

Barbosa FM (2008) Estudo do potencial de regeneração natural: uma análise da chuva de sementes e do estrato regenerante da vegetação ciliar na bacia hidrográfica do rio Taperoá, semiárido paraibano, Brasil. Tese (Doutorado em Ecologia e Recursos Naturais) Centro de Ciências Biológicas e da Saúde da Universidade Federal de São Carlos: UFSCar, $95 \mathrm{f}$.

Barroso GM, Morin MP, Peixoto, AL, Ichaso, CLF (2004). Frutos e Sementes. Editora UFV; ISBN: 8572690395; 443p.

Campos EP, Vieira MF, Silva AF, Martins SV, Carmo MS, Moura VM, Ribeiro ASS (2009) Chuva de sementes em Floresta Estacional Semidecidual em Viçosa, MG, Brasil. Acta Botânica Brasilica. 23 (2): 451-458. DOI: https://doi.org/10.1590/S010233062009000200017

Castillo RFD, Ríos MP (2008) Mudanças na chuva de sementes durante a sucessão secundária em uma região montana tropical da floresta da nuvem em Oaxaca, México. Journal of Tropical Ecology, 24(4): $\quad$ 433-444. DOI: https://doi.org/10.1017/S0266467408005142

CEMESE (2012) Centro de meteorologia de Sergipe. Secretaria do Meio Ambiente e Recursos Hídricos. Meteorologia do município de Porto da Folha. Disponível em: http://www.semarh.se.gov.br/meteorologia/modules /tinyd0/index.php?id=3 Acesso em: 20 de Janeiro de 2012.

Chase MW, Christenhusz MJM, Fay MF, Byng JW, Judd WS, Soltis DE, Mabberley DJ, Sennikov AN, Soltis PS, Stevens PF (2016). An update of the Angiosperm Phylogeny Group Classification for the Orders and Families of Flowering Plants. Angiosperm Phylogeny Group (APG) IV. Botanical Journal of the Linnean Society. 181(1): 1-20. DOI: https://doi.org/10.1111/boj.12385

Dantas BF, Matias JR, Mendes RB, Ribeiro RC (2014) “As sementes da Caatinga são...”: um levantamento das características das sementes da Caatinga. Informativo Abrantes, 24(3): 18-23.

Du Y, Mi X, Ma K (2012) Comparison of seed rain and seed limitation between community understory and gaps in a subtropical evergreen forest. Acta Oecologica, 44: 11-19. DOI: https://doi.org/10.1016/j.actao.2011.06.001
Feliciano ALP, Marangon LC, Holanda, DAC (2008). Morfologia de sementes, de plântulas e de plantas jovens de aroeira (Myracrodruon urundeuva Allemão). Revista de Biologia e Ciências da Terra, 8(1): 198-206.

Foster, R. B (1992) Ciclo estacional de caída de frutos en la isla de Barro Colorado. In: E. G. Leigh, A. S. Rand \& D. M. Windsor (eds.), Ecología de un bosque tropical, Smithsonian Tropical Research Institute. Balboa. p. 219-241.

Griz IMS, Machado ICS (2001) Fruiting phenology and seed dispersal syndromes in Caatinga, a tropical dry forest in the Northeast of Brazil. Journal of Tropical Ecology. 17: 303-321. DOI: https://doi.org/10.1017/S0266467401001201

Howe HF, Smallwood J (1982) Ecology of seed dispersal. Annual Review Ecology and Systematics, 13: 201-228. DOI: https://doi.org/10.1146/annurev.es.13.110182.0012 21

Lima AB, Rodal MJN, Silva ACBL (2008) Chuva de sementes em uma área de vegetação de caatinga no estado de Pernambuco. Rodriguésia, 59(4): 649-658. DOI: https://doi.org/10.1590/2175-7860200859402

Lima EN, Araújo EL, Sampaio EVSB, Ferraz EMN, Silva KA, Pimentel, RMM (2007) Fenologia e dinâmica de duas populações herbáceas da Caatinga. Revista de Geografia, 24(1): 120-136.

Magurran AE (1988). Ecological diversity and its measurement. Princeton, Princeton University, $179 \mathrm{p}$.

Martínez-Garza C, Osorio-Beristain M, ValenzuelaGalván D, Nicolás-Medina A (2011) Intra and interannual variation in seed rain in a secondary dry tropical forest excluded from chronic disturbance. Forest Ecology and Management, 262(12): 2207-2218. DOI: https://doi.org/10.1016/j.foreco.2011.08.013

Martins RM, Batalha MA (2013). Formas de vida, espectro biológico de Raumiaer e fisionomia da vegetação. Capítulo 2, p. 44-85. In.: Felfili JM, Eisenlohr PV, Melo MMRF, Andrade LA, MeiraNeto JAA (Org.) Fitossociologia no Brasil: métodos e estudos de casos, Volume I. Viçosa-MG: Editora UFV, 556 p.

Medeiros JX, Silva GH, Ramos TM, Oliveira RB, Nóbrega AM, Amorim LPN (2015) Composição e diversidade florística de banco de sementes em solo de área de Caatinga. Revista Holos, 31(8): 3-14. DOI: https://doi.org/10.15628/holos.2015.2098

Morellato LPC, Talora DC, Takahasi A, Benke CSC, Romera EC, Ziparro V (2000) Phenology of atlantic rain Forest trees: a comparative study. Biotropica, 
32:811-823. DOI: https://doi.org/10.1111/j.17447429.2000.tb00620.x

Mueller-Dombois D, Ellenberg H (1974). Aims and methods of vegetation ecology. Nova York: Wiley. Paz GVD, Silva KAD, Almeida-Cortez JSD (2016) Banco de sementes em áreas de caatinga com diferentes graus de antropização no Sertão de Itaparica-PE. Journal of Environmental Analysis and Progress, 1(1): 61-69. DOI: https://doi.org/10.24221/jeap.1.1.2016.987.61 $-69$

Pielou EC (1975). Ecological diversity. New York: Wiley. 165 p.

Pietro-Souza W, Silva NMD, Campos ÉPD (2014) Chuva de sementes em remanescentes florestais de Campo Verde, MT. Revista Árvore, 38(4): 689-698. DOI: $\quad$ https://doi.org/10.1590/S010067622014000400012

Ribeiro TDO, Bakke IA, Souto PC, Bakke OA, Lucena DDS (2017) Diversidade do banco de sementes em diferentes áreas de Caatinga manejadas no semiárido da Paraíba, Brasil. Ciência Florestal, 27(1): 203-213. DOI: https://doi.org/10.5902/1980509826459

Santos DMD, Silva KAD, Santos JMFFD, Araújo, EDL (2018) Soil seed bank and its importance in the natural regeneration of degraded areas. Ethnobiology and Conservation, 7(5): 1-7.

Santos, DMD, Silva KAD, Santos JMFFD, Lopes CGR, Pimentel RMDM, Araújo EDL (2010) Variação espaço-temporal do banco de sementes em uma área de floresta tropical seca (Caatinga), Pernambuco. Revista de Geografia, 27(1): 234-253.

Silva ACDC, Prata APDN, Mello AAD, Santos ACADS (2013a) Síndromes de dispersão de Angiospermas em uma Unidade de Conservação na Caatinga (SE) Brasil, Hoehnea, 40(4): 601-609. DOI: $\quad$ https://doi.org/10.1590/S223689062013000400003

Silva KAD, Santos DMD, Santos JMD, Ulysses P, Ferraz EM, Araújo EDL (2013b) Spatio-temporal variation in a seed bank of a semi-arid region in northeastern Brazil. Acta oecologica, 46: 25-32. DOI: https://doi.org/10.1016/j.actao.2012.10.008

Silva MCNA, Rodal MJN (2009) Padrões das síndromes de dispersão de plantas em áreas com diferentes graus de pluviosidade (PE) Brasil. Acta Botanica Brasilica, 23(4): 1040-1047. DOI: https://doi.org/10.1590/S010233062009000400014

Silva RKSD, Feliciano ALP, Marangon LC, Andrade Lima RBD, Santos WBD (2012). Estrutura e síndromes de dispersão de espécies arbóreas em um trecho de mata ciliar, Sirinhaém (PE), Brasil. Pesquisa Florestal Brasileira, 32(69): 1-11. DOI: https://doi.org/10.4336/2012.pfb.32.69.01

Van Der Pijl, L (1982) Principles of dispersal in higher plants. $3^{\mathrm{a}}$. ed. New York: Springer Verlag. $215 \mathrm{p}$. 